\title{
REVIEW
}

\section{Mucosal dendritic cells shape mucosal immunity}

\author{
Sun-Young Chang ${ }^{1}$, Hyun-Jeong $\mathrm{Ko}^{2}$ and $\mathrm{Mi}-\mathrm{Na} \mathrm{Kweon}^{3}$ \\ Dendritic cells (DCs) are key modulators that shape the immune system. In mucosal tissues, DCs act as surveillance systems \\ to sense infection and also function as professional antigen-presenting cells that stimulate the differentiation of naive $\mathrm{T}$ and $\mathrm{B}$ \\ cells. On the basis of their molecular expression, DCs can be divided into several subsets with unique functions. In this review, \\ we focus on intestinal DC subsets and their function in bridging the innate signaling and adaptive immune systems to maintain \\ the homeostasis of the intestinal immune environment. We also review the current strategies for manipulating mucosal DCs for \\ the development of efficient mucosal vaccines to protect against infectious diseases.
}

Experimental \& Molecular Medicine (2014) 46, e84; doi:10.1038/emm.2014.16; published online 14 March 2014

Keywords: antigen capture; helper T-cell subset; mucosal dendritic cells; mucosal vaccine; secretory IgA

\section{INTRODUCTION}

Mucosal tissues contain various lymphoid cells. Of these, accessory cells act as sentinels to sense invading organisms, $\mathrm{T}$ cells attack and clear pathogens, and B cells secrete IgA. These cells reside among large numbers of commensal microorganisms that also contribute to host defense through metabolic competition ${ }^{1}$ or by enforcing the host's immune barrier. $^{2}$ To maintain homeostasis with commensals on mucosal surfaces, there is a specialized immune system associated with mucosal environments. The intestineespecially the small intestine-strongly drives immune suppression against exogenous antigens. Food antigens can induce oral tolerance by generating inducible regulatory $\mathrm{T}$ (Treg) cells. ${ }^{3}$ Antigen-presenting cells, such as dendritic cells (DCs) or macrophages, survey the mucosal environment using innate pattern recognition receptors. These cells can adjust and balance the suppressive regulation of commensals or innocuous antigens and protect against pathogens by generating various types of helper $\mathrm{T}\left(\mathrm{T}_{\mathrm{H}}\right)$ and $\mathrm{CD} 8{ }^{+} \mathrm{T}$ cells as well as secretory IgA (SIgA) antibodies. Before efficient mucosal vaccines can be developed, it is imperative to achieve an understanding of both the mucosal immune system and the regulatory mechanisms of immune cells. Further, strategies to overcome regulatory mechanisms will be essential. Here, we provide an overview of the intestinal immune systems, focusing on the unique subsets and functional features of intestinal DCs, and consider key biological and technical aspects of mucosal vaccine design. We then summarize the current status of mucosal vaccine development, including strategies involving modulation of mucosal DC activation.

\section{INTESTINAL DC SUBSETS}

As DC subsets in the small intestine have been well studied, we closely examined published studies describing lamina propria DCs in the small intestine. Although DCs are frequently characterized as $\mathrm{CD}_{11 c^{+}}$major histocompatibility class (MHC) $\mathrm{II}^{+}$cells, this group likely contains macrophages. The CD11 $\mathrm{c}^{\text {high }} \mathrm{MHC}$ class II ${ }^{\text {high }}$ population comprises genuine DCs, whereas the CD11 $c^{\text {low }}$ MHC class $\mathrm{II}^{\text {low }}$ population is composed of macrophages. ${ }^{4}$ Intestinal lamina propria DCs have different origins and functions. ${ }^{5}$ Differentiation of

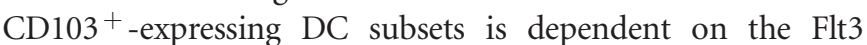
ligand, whereas CX3CR1-expressing DCs and macrophages are dependent on CSF-1R (Figure 1). Most DCs can be largely classified as non-migratory DCs, which are tissue-resident, or migratory DCs, which can migrate into draining lymph nodes with sampled antigen and be infiltrated during inflammation. DC migration is tightly controlled by the expression of CCR7. ${ }^{6}$ Representative DC subsets and their functions are listed in Table 1; some subsets might overlap by phenotype. Of the DC populations, $\mathrm{CD}_{103}{ }^{+}$has been the best studied. In addition, reports regarding resident $\mathrm{CX} 3 \mathrm{CR} 1^{+} \mathrm{DCs}$ (or phagocytes) have increased recently. In the absence of Myd88 or under conditions of antibiotic-induced dysbiosis, non-invasive bacteria are trafficked to the mesenteric lymph nodes (MLNs) in a CCR7-dependent manner, where they induce both T-cell

\footnotetext{
${ }^{1}$ Laboratory of Microbiology, College of Pharmacy, Ajou University, Suwon, Korea; ${ }^{2}$ Laboratory of Microbiology and Immunology, College of Pharmacy, Kangwon National University, Chuncheon, Korea and ${ }^{3}$ Mucosal Immunology Section, International Vaccine Institute, Seoul, Korea Correspondence: Dr S-Y Chang, Laboratory of Microbiology, College of Pharmacy, Ajou University, Suwon 443-749, Korea.

E-mail: sychang@ajou.ac.kr
}

Received 27 November 2013; accepted 21 December 2013 
responses and IgA production. Trafficking is carried out by CX3CR $1{ }^{\text {hi }}$ phagocytes, which are non-migratory. ${ }^{7}$ TNF- $\alpha /$ iNOS-producing DCs (Tip DCs) express TNF and inducible nitric oxide synthase (iNOS) and release large amounts of nitric oxide after recognizing commensal bacteria through tolllike receptors (TLRs). ${ }^{8}$ The detailed functions of each subset will be discussed later (Table 2).

\section{ANTIGEN UPTAKE}

The antigen uptake process may be the first step during the process in which DCs link the innate and adaptive immune systems. DCs can uptake antigens by both direct and indirect pathways. In turn, the indirect pathway can be subdivided into a number of categories: $M$ cell-dependent (Figure 2a), goblet cell-dependent (Figure 2b), neonatal Fc receptor (FcRn)-dependent (Figure 2c) and apoptosis-dependent (Figure 2d). The $\mathrm{M}$ cell-dependent pathway is involved in antigen entry into specialized $M$ cells in the follicle-associated epithelium of Peyer's patches (Figure 2a)..$^{9} \mathrm{M}$ cells transcytose luminal antigen and enteric bacteria inside the subepithelial dome. Underlying DCs and macrophages can capture the antigen delivered by $\mathrm{M}$ cells. $\mathrm{M}$ cells also exit the villous epithelium and contribute to antigen sampling in the lamina propria. ${ }^{10}$ Villous $\mathrm{M}$ cells are induced under inflammatory conditions. ${ }^{11}$ FcRn mediates the bidirectional transport of IgG, resulting in transport into the lumen and trafficking back to the lamina propria of antigen-antibody immune complexes (Figure 2c). ${ }^{12}$ Antigens associated with apoptotic epithelial cells can be taken up by DCs either at steady state or after microbial infection (Figure 2d). ${ }^{13}$ Goblet cells function as passages that deliver low-molecular-weight soluble antigens from the intestinal lumen to underlying $\mathrm{CD} 103^{+}$DCs in the lamina propria, a process termed goblet cell-associated antigen passage (GAP) (Figure 2b). ${ }^{14}$ DCs can also extend dendrites

\section{Small Intestinal Phagocytes}

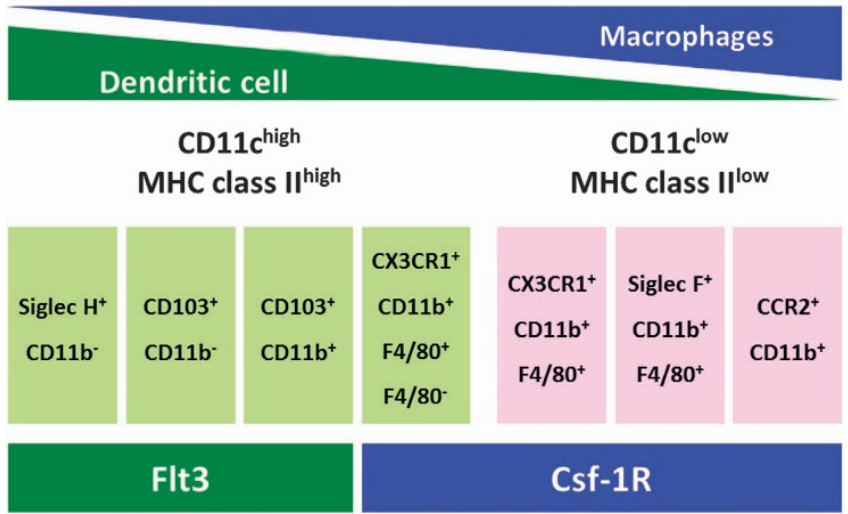

Figure 1 Surface phenotypes in subsets of small intestinal phagocytes. DCs are CD11 $\mathrm{c}^{\text {high }}$ and MHC class $\mathrm{I}^{\text {high}}$, whereas macrophages are CD11 $\mathrm{c}^{\text {low }}$ and $\mathrm{MHC}$ class $\mathrm{Il}^{\mathrm{low}}$. Two major DC subset populations are $\mathrm{CD} 103^{+} \mathrm{CD} 11 b^{+}$and $\mathrm{CX} 3 \mathrm{CR} 1{ }^{+} \mathrm{CD} 11 b^{+}$. The differentiation of $\mathrm{CD}_{103^{+}}{ }^{-}$expressing $\mathrm{DC}$ subsets is dependent on Flt3L, whereas CX3CR1-expressing DCs and macrophages are dependent on CSF-1R. between epithelial cells to directly sample antigens from the intestinal lumen (Figure 3). CX3CR1 ${ }^{+}$DCs can sample Salmonella bacteria by extending long dendrites across the epithelium, which is a CX3CR1-dependent process. ${ }^{15}$ In addition to luminal antigen, lamina propria $\mathrm{CX} 3 \mathrm{CR} 1^{+} \mathrm{DCs}$ facilitate the surveillance of circulatory antigens and act as a conduit for the processing of self- and intestinally-absorbed antigens. ${ }^{16}$ One recent report showed that $\mathrm{CD} 103^{+}$DCs patrol among enterocytes while extending dendrites toward the lumen, likely using tight junction proteins to penetrate the epithelium. ${ }^{17}$ These intraepithelial CD103 ${ }^{+}$DCs could be recruited into the intestinal epithelium by luminal bacteria to sample bacterial antigens for presentation.

\section{T-CELL IMMUNITY BY INTESTINAL DCS}

When DC-sampled antigen undergoes maturation, antigen processing and presentation process occur simultaneously. Differentiation of T-cell subsets as instructed by intestinal DCs is summarized in Figure 4. Several studies have reported that $\mathrm{CD}_{103}{ }^{+}$DCs can induce regulatory $\mathrm{CD} 4^{+}$Foxp3 ${ }^{+}$ $\mathrm{T}$ cells via retinoic acid (RA), a metabolic derivative of vitamin A found in food, and TGF- $\beta ;^{18-20}$ however, another study showed that compared with DCs, $\mathrm{CD} 11 \mathrm{~b}^{+} \mathrm{F} 4 / 80^{+} \mathrm{CD} 11 \mathrm{c}^{-}$ macrophages in the lamina propria are more potent inducers of Treg cells. ${ }^{21}$ Intestinal CX3CR ${ }^{+}$macrophages support the expansion of Treg cells by means of IL-10 production to harness immune tolerance. ${ }^{22} \mathrm{CX} 3 \mathrm{CR} 1^{+}$DCs can sample and process both circulatory and luminal antigens. ${ }^{16}$ Cross-presentation by resident $\mathrm{CX} 3 \mathrm{CR} 1^{+}$DCs induces differentiation into $\mathrm{CD}^{+}$ $\mathrm{T}$ cells that express IL-10, IL-13, and IL-9. These CD8 ${ }^{+} \mathrm{T}$ cells can inhibit pro-inflammatory $\mathrm{CD}^{+}{ }^{+} \mathrm{T}$-cell activation in vitro and in vivo in intestinal inflammatory disease in an IL-10-dependent manner. Finally, these $\mathrm{CD}^{+} \mathrm{T}$ cells are dispersed at the lamina propria or migrate to the epithelium in a CCR6-dependent manner, and they comprise the regulatory $\mathrm{CD} 8 \alpha \beta^{+} \mathrm{TCR} \alpha \beta^{+}$T-cell population. Therefore, both $\mathrm{CD} 103^{+}$and $\mathrm{CX} 3 \mathrm{CR} 1^{+}$DCs induce two arms of regulatory $\mathrm{CD}^{+}$and $\mathrm{CD}^{+}{ }^{+} \mathrm{T}$ cells to maintain intestinal immune homeostasis at a steady state (Figure 4).

$\mathrm{CD}_{103}{ }^{+} \mathrm{CD} 11 \mathrm{~b}^{+}$DCs are the primary migratory DC population within the small intestinal lamina propria and can be infiltrated under inflammatory conditions. ${ }^{23,24}$ $\mathrm{CD} 103{ }^{+} \mathrm{CD} 11 \mathrm{~b}^{+}$DCs produce IL-6 upon TLR stimulation and subsequently induce $\mathrm{T}_{\mathrm{H}} 17$ cell differentiation. ${ }^{25}$ Ivanov et $a l .^{26}$ reported that segmented filamentous bacteria, which are murine commensal bacteria, are sufficient for $\mathrm{T}_{\mathrm{H}} 17$ differentiation. This finding suggests that $\mathrm{CD} 103^{+} \mathrm{CD} 11 \mathrm{~b}^{+}$ DCs might interact with segmented filamentous bacteria and generate signals to induce $\mathrm{T}_{\mathrm{H}} 17$. CD103 ${ }^{+} \mathrm{CD} 8 \alpha^{+}$DCs express TLR3, TLR7 and TLR9, and they produce IL- 6 and IL-12p40 following TLR ligand stimulation. ${ }^{26}$ These DCs induce antigen-specific IgG in serum, a $T_{H} 1$ response and cytotoxic T lymphocyte (CTL) activity in vivo. When stimulated by the TLR5 ligand flagellin, TLR5 ${ }^{+}$DCs promote the differentiation of antigen-specific $\mathrm{T}_{\mathrm{H}} 17$ and $\mathrm{T}_{\mathrm{H}} 1$ cells. ${ }^{27}$ CX3CR $1^{+}$DCs phagocytose and kill intracellular bacteria; however, their 
Table 1 Representative DC subsets in the small intestine

\begin{tabular}{|c|c|c|c|c|}
\hline Name & Phenotype & Characteristic features & Functions & References \\
\hline${\mathrm{CD} 103^{+}}^{+}$ & $\mathrm{CD} 103^{+}$ & CCR7 expression: migration into LNs & $\mathrm{CD}^{+}{ }^{+} \mathrm{Foxp}^{+}{ }^{+}$Treg generation & $18-20,44$ \\
\hline \multirow[t]{4}{*}{ DCs } & \multirow[t]{4}{*}{$\mathrm{CD}_{11} \mathrm{~b}^{+}$} & RALDH expression: RA production & IgA class switching & 31 \\
\hline & & Antigen uptake by extending long dendrites or goblet cell- & Imprinting of lymphocyte gut homing by & 45,46 \\
\hline & & associated antigen passage (GAP) & expression of CCR9 & 23 \\
\hline & & TLR stimulation: IL-6 production & $\mathrm{T}_{\mathrm{H}} 17$ generation & 25 \\
\hline $\mathrm{CD}_{10} 3^{+}$ & $\mathrm{CD} 103^{+} \mathrm{CD}^{+}$ & Expression of TLR3, TLR7, and TLR9 & $\mathrm{T}_{\mathrm{H}} 1$ response and $\mathrm{CTL}$ activity & 26 \\
\hline $\mathrm{CD}^{+}+\mathrm{DCs}$ & CD11 blow & Production of IL-6 and IL-12p40 & & \\
\hline $\mathrm{CX} 3 \mathrm{CR} 1+$ & $\mathrm{CX} 3 \mathrm{CR} 1^{+}$ & No CCR7 expression: tissue-resident & Generation of regulatory $\mathrm{CD} 8 \alpha \beta^{+} \mathrm{TCR} \alpha \beta^{+}$ & 15 \\
\hline \multirow[t]{2}{*}{ DCs } & $\mathrm{F} 4 / 80^{+}$ & Uptake of circulatory or luminal antigen by extending long & intraepithelial lymphocytes (IELs) & 16 \\
\hline & $\mathrm{CD}_{11} \mathrm{~b}^{+}$ & dendrites & & \\
\hline \multirow[t]{2}{*}{ Tip DCs } & $\mathrm{TNF}_{-} \alpha^{+} \mathrm{iNOS}^{+}$ & TGF- $\beta$ & IgA production & 8 \\
\hline & $\mathrm{CD}_{11} \mathrm{~b}^{+}$ & APRIL and BAFF production & & \\
\hline TLR5 + & TLR5 + CD1 $1 c^{\text {hi }}$ & IL-6 production & Differentiation of antigen-specific $T_{H} 17$ and & 27 \\
\hline \multirow[t]{2}{*}{ DCs } & CD1 $1 b^{\text {hiF }} 4 / 80+$ & RALDH expression: RA production & $\mathrm{T}_{\mathrm{H}} 1$ cells & \\
\hline & $\mathrm{CD} 103^{+}$ & Expression of TLR5 and TLR9 & Generation of IgA-producing cells & \\
\hline \multirow[t]{2}{*}{ pDCs } & $\mathrm{CD} 11 \mathrm{c}^{\mathrm{int}} \mathrm{B} 220^{+}$ & Type I IFN receptor expression & T cell-independent IgA production & 28 \\
\hline & mPDCA1 + & APRIL and BAFF production & & \\
\hline
\end{tabular}

Table 2 Mucosal vaccines that target mucosal DC subsets

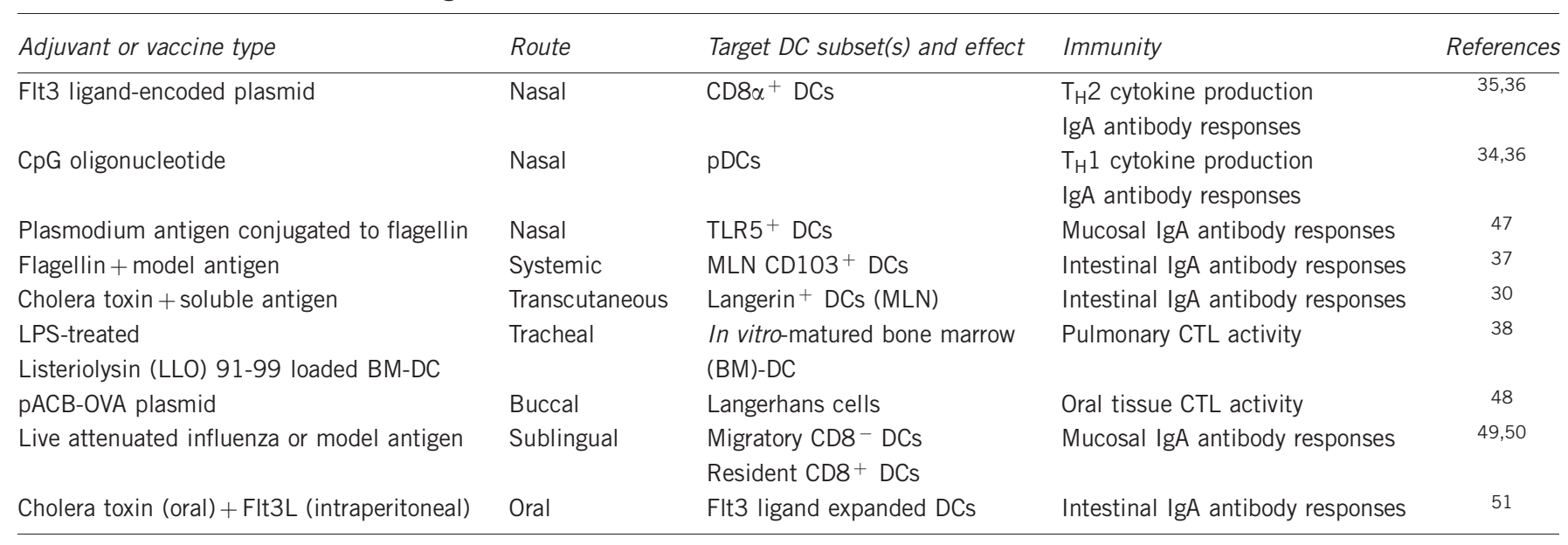

in vivo function remains unclear under inflammatory conditions or during infection.

\section{SECRETORY IgA PRODUCTION BY INTESTINAL DCS}

A unique feature of the mucosal immune system is the local production and secretion of dimeric or multimeric IgA from $\mathrm{B}$ cells. IgA class switching occurs in gut-associated lymphoid tissues, including Peyer's patches, MLNs and isolated lymphoid follicles in the lamina propria. SIgA within the mucosal fluid constitutes the first barrier against pathogen infection and forms a barrier between invading and commensal microorganisms (Figure 5). Mucosal DCs support B-cell activation, IgA isotype class-switch DNA recombination (CSR) and differentiation into IgA-secreting plasma cells with the assistance of $\mathrm{T}$ cells or by means of a $\mathrm{T}$ cell-independent pathway that expresses B cell-activating factor. The latter belongs to the
TNF family (BAFF), and as does a proliferation-inducing ligand (APRIL). Intestinal plasmacytoid DCs (pDCs) induce IgA production by expressing BAFF and APRIL. ${ }^{28}$ Tip DCs release large amounts of nitric oxide after recognizing commensal bacteria through TLRs. $^{8}$ Nitric oxide enhances IgA CSR and production by upregulating TGF $\beta$ RII expression on B cells and by inducing the expression of BAFF and APRIL in DCs through unknown mechanisms. In the intestinal environment, RA and TGF- $\beta$ enforce efficient IgA class switching. In fact, retinaldehyde dehydrogenase type 2 (RALDH2) expressed DCs, but not all mucosal DCs can induce IgA CSR. ${ }^{29}$ Intestinal CD103 ${ }^{+} \mathrm{CD} 11 \mathrm{~b}{ }^{+}$DCs, Tip DCs and TLR5 $^{+}$DCs express RALDH and convert it into RA. In turn, RA can be used for IgA production. ${ }^{8,27}$ Langerinexpressing DCs in the MLNs that emerge following transcutaneous vaccination can also induce vaccine antigen-specific 
IgA production that is dependent on RA. ${ }^{30}$ Moreover, intestinal DCs imprint gut homing of IgA-secreting plasma cells via RA, which induces the expression of gut homing receptors, such as $\alpha_{4} \beta_{7}$ integrin and CCR9, on lymphocytes. ${ }^{31}$ As shown in several studies, RA is essential for maintaining the intestinal immune environment because it is a determinant for antibody isotype, $\mathrm{T}_{\mathrm{H}}$ cell and DC subsets. ${ }^{32,33}$ The main goal of a mucosal vaccine is to elicit vaccine antigenspecific IgA production in the mucosal tissue of the infection route.

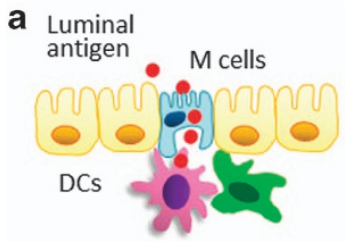

M cell-dependent

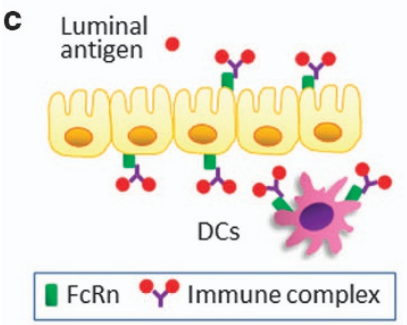

FcRn-dependent

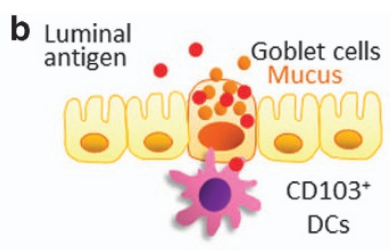

Goblet cell-dependent

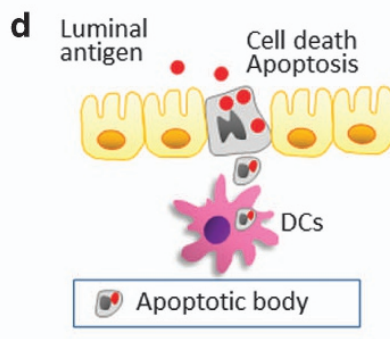

Apoptosis-dependent
Figure 2 Indirect pathways for antigen uptake by intestinal DCs. These pathways can be classified as M cell-dependent (a), goblet cell-dependent (b), neonatal Fc receptor (FcRn)-dependent (c) and apoptosis-dependent (d).

\section{MUCOSAL VACCINATION VIA THE MODULATION OF MUCOSAL DCS}

Mucosal immune responses are most efficiently induced by the administration of vaccines onto mucosal surfaces, whereas vaccines injected deep into skin tissue (subcutaneously) or muscle (intramuscularly) are usually poor inducers of mucosal immunity and are therefore less effective against infection at mucosal surfaces. Mucosal vaccines given at mucosal surfaces must overcome the same physical host defense challenges as

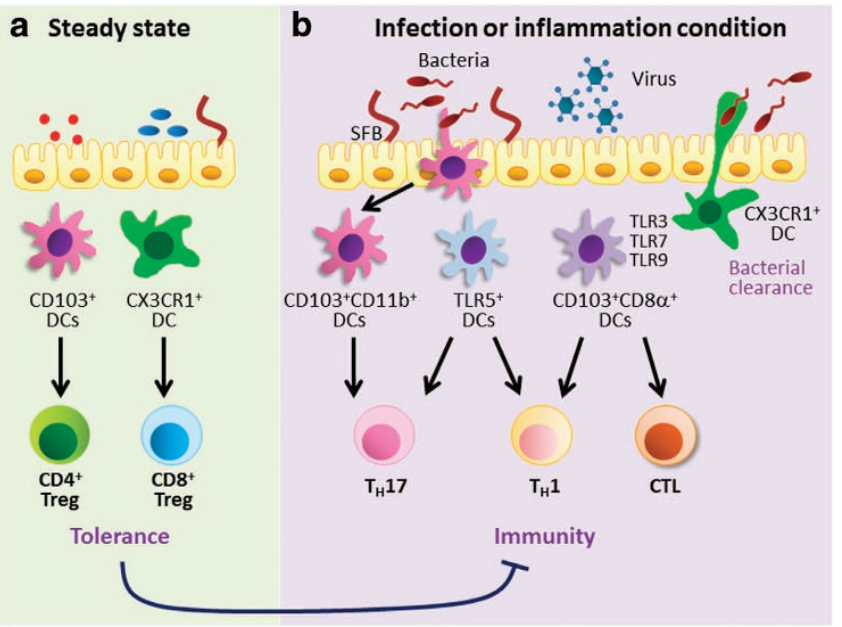

Figure $4 \mathrm{~T}$ cell generation by intestinal DCs. (a) Under steady-state conditions, lamina propria $\mathrm{CD}_{103}{ }^{+} \mathrm{DCs}$ induce $\mathrm{Foxp} 3^{+} \mathrm{CD} 4{ }^{+}$ Tregs to deliver innocuous antigen. CX3CR $1^{+}$DCs can induce IL-10 expressing $\mathrm{CD}^{+}$Tregs to both luminal and circulatory antigens. (b) During infection or under inflammatory conditions, $\mathrm{CD} 103^{+} \mathrm{DCs}$ and $\mathrm{TLR}^{+} \mathrm{DCs}$ induce $\mathrm{T}_{\mathrm{H}} 17$ cells. TLR5 ${ }^{+} \mathrm{DCs}$ and $\mathrm{CD} 103^{+} \mathrm{CD} 8 \alpha^{+}$DCs can induce $\mathrm{T}_{H} 1$ cells via TLR signaling. $\mathrm{CD} 103+\mathrm{CD} 8 \alpha+$ DCs can induce CTLs.

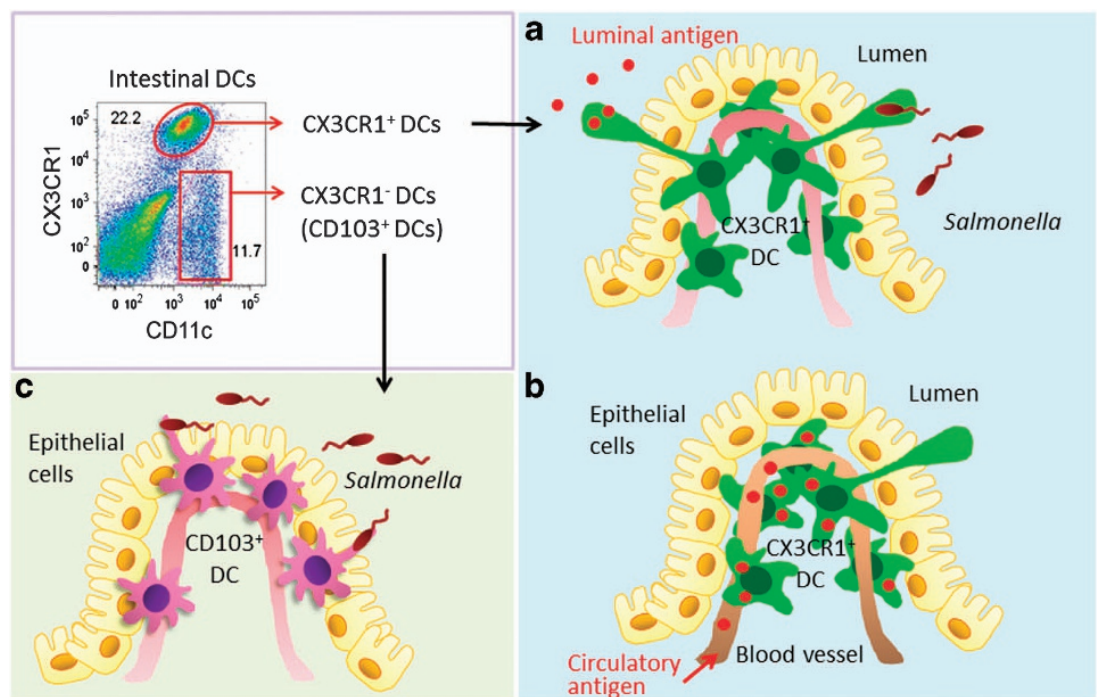

Figure 3 Antigen uptake using intraepithelial dendrites of lamina propria DCs. (a) CX3CR $1^{+}$DCs can sample Salmonella organisms as well as luminal soluble bacterial antigens by extending long dendrites across the epithelium via a CX3CR1-dependent mechanism. (b) $\mathrm{CX} 3 \mathrm{CR} 1^{+} \mathrm{DCs}$ facilitate the surveillance of circulatory antigens. (c) Intraepithelial CD103+ DCs can be recruited into the intestinal epithelium by luminal bacteria to sample bacterial antigens. 


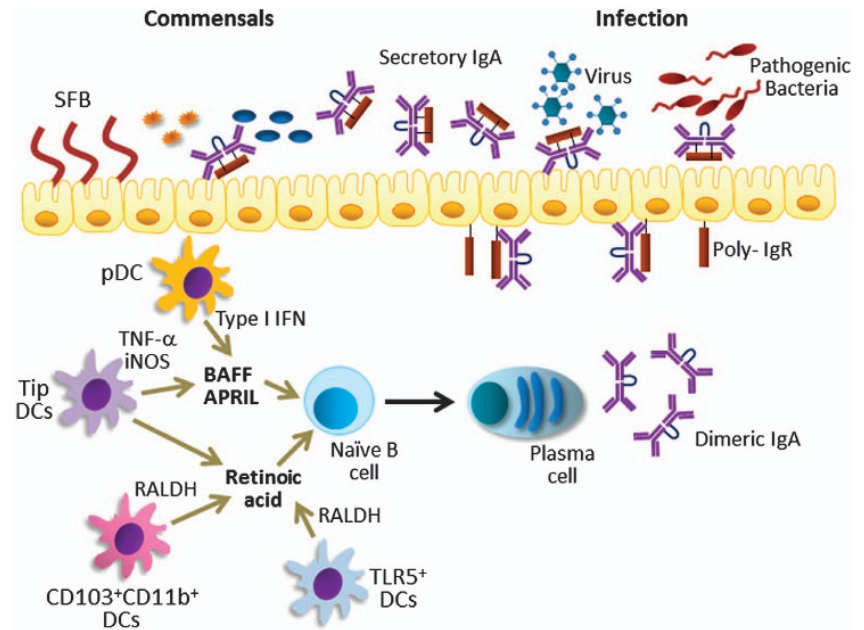

Figure 5 Secretory IgA production by intestinal DCs. Intestinal pDCs and tip DCs induce IgA production by expressing BAFF and APRIL. Intestinal CD103+CD11b ${ }^{+}$DCs, tip DCs and TLR5 ${ }^{+}$DCs express RALDH2 that is converted into RA and can be used for IgA production.

microbial pathogens: They are diluted in mucosal secretions, captured in a sticky barrier of mucus, attacked by degradation enzymes and excluded by tight epithelial barriers. Therefore, relatively large doses of vaccine are required for mucosal delivery. Vaccine formulations for targeted delivery must have an effective mucosal adjuvant to surmount tolerance and mimic infectious conditions. For several reasons, live attenuated mucosal vaccines are likely to be more effective than injected vaccines. First, because they are naturally particulate, antigens will selectively adhere to M-cell mucosal surfaces, enabling efficient uptake. Second, via the use of pattern molecules, they should efficiently stimulate innate signals on innate effector cells (especially DCs). Third, they will elicit appropriate adaptive immune responses for clearance of the target pathogen. Another DC-targeted vaccine strategy is the use of appropriate adjuvants, such as DC growth factor or TLR ligand, that are expressed on mucosal DCs (Table 2). Plasmids encoding Flt3 ligand and CpG oligonucleotide selectively target $\mathrm{CD} 8 \alpha^{+}$DCs and pDCs, respectively, when administered nasally. ${ }^{34-36} \mathrm{CD} 8 \alpha^{+}$DCs promote $\mathrm{T}_{\mathrm{H}} 2$ cytokine production, whereas pDCs induce $\mathrm{T}_{\mathrm{H}} 1$ cytokine production to elicit co-administered antigen-specific IgA antibody responses and cell-mediated immunity. In one study, when soluble antigen plus cholera toxin was applied to intact skin, MLN langerin ${ }^{+}$DCs mediated gut IgA production in an RAdependent manner. ${ }^{30}$ Similar to the use oftranscutaneous systemic vaccination to induce gut immunity, systemic immunization with flagellin can recruit $\mathrm{CD}_{103}{ }^{+}$DCs into MLNs and subsequently induce intestinal IgA antibody responses. ${ }^{37}$ Intra-tracheal application of LPS-treated immunodominant CTL epitope-loaded DCs is also a promising strategy for generating CTLs that are protective against respiratory infections caused by intracellular pathogens. ${ }^{38}$
The C-type lectins are a family of calcium-dependent receptors expressed on the surface of innate cells, such as DCs. ${ }^{33}$ DC-targeted delivery strategies have utilized the wellcharacterized DC receptor DEC-205 (CD205) and langerin (CD207). By reinforcing the immunizing functions of mature DCs, antibody-mediated antigen targeting via DEC-205, a C-type lectin receptor, increases the efficiency of vaccination for inducing T-cell immunity. ${ }^{39}$ Without a strong stimulus through innate pattern recognition receptors, DC-captured soluble antigen induces Treg cells to maintain immune tolerance. To induce protective immunity by vaccination, it is necessary to boost the host's innate stimulus. One study found that when vaccine antigen is delivered with a strong adjuvant (that is, cholera toxin transcutaneously injected into intact skin), emergent langerin-expressing mucosal DCs in the MLNs could modulate intestinal IgA responses..$^{30}$ Although the targeting of antigen-presenting cells is not unique to mucosal vaccination strategies, it could help potentiate stronger immune responses to antigens that are delivered mucosally.

Another promising approach for mucosal vaccine development involves enancing antigen uptake by antigen sampling via specialized mechanisms in addition to DCs. It is possible that antigen uptake may need to occur via more than one pathway. To date, studies have used M cell-targeted delivery and lectin targeting strategies on M cells or directly on DCs. The uptake of particulate antigen by $\mathrm{M}$ cells or adhesion to specific M-cell receptors mimics the entry of pathogens into these cells and enhances antigen uptake. This phenomenon was illustrated by the promising findings of a study in which targeting of an $\mathrm{M}$ cell-specific carbohydrate moiety using NKM 16-2-4 successfully induced IgA responses. ${ }^{40}$ Additionally, an FcRn-targeted strategy effectively induced HIV-1 antigen-specific immunity to genital infection. ${ }^{41}$

The use of RA as a vaccine adjuvant enhances IgA responses, $\mathrm{CD}^{+}{ }^{+} \mathrm{T}$-cell responses and mucosal protection from viral challenge. ${ }^{42}$ To improve phagocytic antigen uptake, particulate delivery systems based on synthetic or natural polymers offer opportunities to control the methods, timing and amount of antigens delivered. ${ }^{43}$ These polymers include chitosan, PLGA microparticles, liposomes, immune stimulating complex, nanocapsules and nanoparticles.

\section{CONCLUSION AND FUTURE PERSPECTIVES}

In this review, we focused on the integral role of DCs in shaping the unique mucosal immune system, especially the lamina propri of the small intestine. Depending on the DC subset and environmental conditions, DCs can elicit differential but appropriate immune responses to commensal and pathogenic microbial species, resulting in protection against infectious disease. Knowledge about the novel mucosal immune system has been largely accumulated within the last decade since the advent of advanced experimental techniques for mucosal tissues, the increased availability of germ-free mice and the development advanced techniques for metagenomic analysis of commensals. Recent findings indicate that mucosal DCs and immune effectors may function together to prevent 
and control infectious diseases. Therefore, the current challenge is to apply this knowledge to vaccine design and to carry out collaborative, comparative and integrated studies for vaccine development. Much work will be required to modulate mucosal DCs before strategies can be implemented to exploit the full potential of mucosal vaccines.

\section{CONFLICT OF INTEREST}

The authors declare no conflict of interest.

\section{ACKNOWLEDGEMENTS}

This work was supported by the National Research Foundation of Korea (NRF), which is funded by the Ministry of Education, Science and Technology (No. 2011-0006965 and 2012-0000805).

1 Fukuda S, Toh H, Hase K, Oshima K, Nakanishi Y, Yoshimura K et al Bifidobacteria can protect from enteropathogenic infection through production of acetate. Nature 2011; 469: 543-547.

2 Ciorba MA, Riehl TE, Rao MS, Moon C, Ee X, Nava GM et al. Lactobacillus probiotic protects intestinal epithelium from radiation injury in a TLR-2/ cyclo-oxygenase-2-dependent manner. Gut 2012; 61: 829-838.

3 Mucida D, Kutchukhidze N, Erazo A, Russo M, Lafaille JJ, Curotto de Lafaille MA. Oral tolerance in the absence of naturally occurring Tregs. J Clin Invest 2005; 115: 1923-1933.

4 Denning TL, Norris BA, Medina-Contreras O, Manicassamy S, Geem D, Madan R et al. Functional specializations of intestinal dendritic cell and macrophage subsets that control Th17 and regulatory T cell responses are dependent on the T cell/APC ratio, source of mouse strain, and regional localization. J Immunol 2011; 187: 733-747.

5 Varol C, Vallon-Eberhard A, Elinav E, Aychek T, Shapira Y, Luche H et al. Intestinal lamina propria dendritic cell subsets have different origin and functions. Immunity 2009; 31: 502-512.

6 Jang MH, Sougawa N, Tanaka T, Hirata T, Hiroi T, Tohya K et al. CCR7 is critically important for migration of dendritic cells in intestinal lamina propria to mesenteric lymph nodes. J Immunol 2006; 176: 803-810.

7 Diehl GE, Longman RS, Zhang JX, Breart B, Galan C, Cuesta A et al. Microbiota restricts trafficking of bacteria to mesenteric lymph nodes by $\mathrm{CX}_{3} \mathrm{CR}^{\text {hi }}$ cells. Nature 2013; 494: 116-120.

8 Tezuka H, Abe $\mathrm{Y}$, Iwata M, Takeuchi H, Ishikawa H, Matsushita M et al. Regulation of IgA production by naturally occurring TNF/iNOS-producing dendritic cells. Nature 2007; 448: 929-933.

9 Neutra MR, Mantis NJ, Frey A, Giannasca PJ. The composition and function of $\mathrm{M}$ cell apical membranes: implications for microbial pathogenesis. Semin Immunol 1999; 11: 171-181.

10 Jang MH, Kweon MN, Iwatani K, Yamamoto M, Terahara K, Sasakawa C et al. Intestinal villous $M$ cells: an antigen entry site in the mucosal epithelium. Proc Natl Acad Sci USA 2004; 101: 6110-6115.

11 Terahara K, Nochi T, Yoshida M, Takahashi Y, Goto Y, Hatai H et al. Distinct fucosylation of $\mathrm{M}$ cells and epithelial cells by Fut1 and Fut2, respectively, in response to intestinal environmental stress. Biochem Biophys Res Commun 2011; 404: 822-828.

12 Yoshida M, Claypool SM, Wagner JS, Mizoguchi E, Mizoguchi A, Roopenian DC et al. Human neonatal Fc receptor mediates transport of IgG into luminal secretions for delivery of antigens to mucosal dendritic cells. Immunity 2004; 20: 769-783.

13 Huang FP, Platt N, Wykes M, Major JR, Powell TJ, Jenkins CD et al. A discrete subpopulation of dendritic cells transports apoptotic intestinal epithelial cells to T cell areas of mesenteric lymph nodes. J Exp Med 2000; 191: 435-444.

14 McDole JR, Wheeler LW, McDonald KG, Wang B, Konjufca V, Knoop KA et al. Goblet cells deliver luminal antigen to $\mathrm{CD} 103^{+}$dendritic cells in the small intestine. Nature 2012; 483: 345-349.

15 Niess JH, Brand S, Gu X, Landsman L, Jung S, McCormick BA et al. $\mathrm{CX}_{3} \mathrm{CR} 1$-mediated dendritic cell access to the intestinal lumen and bacterial clearance. Science 2005; 307: 254-258.
16 Chang SY, Song JH, Guleng B, Cotoner CA, Arihiro S, Zhao Y et al. Circulatory antigen processing by mucosal dendritic cells controls $\mathrm{CD} 8^{+} \mathrm{T}$ cell activation. Immunity 2013; 38: 153-165.

17 Farache J, Koren I, Milo I, Gurevich I, Kim KW, Zigmond E et al. Luminal bacteria recruit $\mathrm{CD}_{103}{ }^{+}$dendritic cells into the intestinal epithelium to sample bacterial antigens for presentation. Immunity 2013; 38: 581-595.

18 Coombes JL, Siddiqui KR, Arancibia-Carcamo CV, Hall J, Sun CM, Belkaid $\mathrm{Y}$ et al. A functionally specialized population of mucosal $\mathrm{CD}_{103}{ }^{+}$DCs induces Foxp3 ${ }^{+}$regulatory T cells via a TGF-beta and retinoic acid-dependent mechanism. J Exp Med 2007; 204: 1757-1764.

19 Sun CM, Hall JA, Blank RB, Bouladoux N, Oukka M, Mora JR et al. Small intestine lamina propria dendritic cells promote de novo generation of Foxp3 T reg cells via retinoic acid. J Exp Med 2007; 204: $1775-1785$.

20 Mucida D, Park Y, Kim G, Turovskaya O, Scott I, Kronenberg M et al. Reciprocal TH17 and regulatory T cell differentiation mediated by retinoic acid. Science 2007; 317: 256-260.

21 Denning TL, Wang YC, Patel SR, Williams IR, Pulendran B. Lamina propria macrophages and dendritic cells differentially induce regulatory and interleukin 17-producing T cell responses. Nat Immunol 2007; 8: 1086-1094.

22 Hadis U, Wahl B, Schulz O, Hardtke-Wolenski M, Schippers A, Wagner N et al. Intestinal tolerance requires gut homing and expansion of FoxP3 ${ }^{+}$regulatory $\mathrm{T}$ cells in the lamina propria. Immunity 2011; 34: 237-246.

23 Schulz O, Jaensson E, Persson EK, Liu X, Worbs T, Agace WW et al. Intestinal $\mathrm{CD}_{103^{+}}$, but not $\mathrm{CX}_{3} \mathrm{CR} 1^{+}$, antigen sampling cells migrate in lymph and serve classical dendritic cell functions. J Exp Med 2009; 206: 3101-3114.

24 Jaensson E, Uronen-Hansson H, Pabst O, Eksteen B, Tian J, Coombes JL et al. Small intestinal $\mathrm{CD}_{103}{ }^{+}$dendritic cells display unique functional properties that are conserved between mice and humans. J Exp Med 2008; 205: 2139-2149.

25 Persson EK, Uronen-Hansson H, Semmrich M, Rivollier A, Hagerbrand K, Marsal J et al. IRF4 transcription-factor-dependent $\mathrm{CD}_{103}{ }^{+} \mathrm{CD} 11 \mathrm{~b}^{+}$ dendritic cells drive mucosal T helper 17 cell differentiation. Immunity 2013; 38: 958-969.

26 Fujimoto K, Karuppuchamy T, Takemura N, Shimohigoshi M, Machida T, Haseda $\mathrm{Y}$ et al. A new subset of $\mathrm{CD} 103{ }^{+} \mathrm{CD} 8 \mathrm{alpha}{ }^{+}$dendritic cells in the small intestine expresses TLR3, TLR7, and TLR9 and induces Th1 response and CTL activity. J Immunol 2011; 186: 6287-6295.

27 Uematsu S, Fujimoto K, Jang MH, Yang BG, Jung YJ, Nishiyama M et al. Regulation of humoral and cellular gut immunity by lamina propria dendritic cells expressing Toll-like receptor 5. Nat Immunol 2008; 9: 769-776.

28 Tezuka H, Abe Y, Asano J, Sato T, Liu J, Iwata M et al. Prominent role for plasmacytoid dendritic cells in mucosal T cell-independent IgA induction. Immunity 2011; 34: 247-257.

29 Molenaar R, Knippenberg M, Goverse G, Olivier BJ, de Vos AF, O'Toole T et al. Expression of retinaldehyde dehydrogenase enzymes in mucosal dendritic cells and gut-draining lymph node stromal cells is controlled by dietary vitamin A. J Immunol 2011; 186: 1934-1942.

30 Chang SY, Cha HR, Igarashi O, Rennert PD, Kissenpfennig A, Malissen B et al. Cutting edge: Langerin ${ }^{+}$dendritic cells in the mesenteric lymph node set the stage for skin and gut immune system cross-talk. J Immunol 2008; 180: 4361-4365.

31 Mora JR, Iwata M, Eksteen B, Song SY, Junt T, Senman B et al. Generation of gut-homing IgA-secreting B cells by intestinal dendritic cells. Science 2006; 314: 1157-1160.

32 Chang SY, Cha HR, Chang JH, Ko HJ, Yang H, Malissen B et al. Lack of retinoic acid leads to increased langerin-expressing dendritic cells in gutassociated lymphoid tissues. Gastroenterology 2010; 138: 1468-1478. 78 e1-6.

33 Chang SY, Kweon MN. Langerin-expressing dendritic cells in gutassociated lymphoid tissues. Immunol Rev 2010; 234: 233-246.

34 Yi AK, Yoon JG, Yeo SJ, Hong SC, English BK, Krieg AM. Role of mitogenactivated protein kinases in CpG DNA-mediated IL-10 and IL-12 production: central role of extracellular signal-regulated kinase in the negative feedback loop of the CpG DNA-mediated Th1 response. J Immunol 2002; 168: 4711-4720.

35 Kataoka K, McGhee JR, Kobayashi R, Fujihashi K, Shizukuishi S. Nasal Flt3 ligand $\mathrm{cDNA}$ elicits $\mathrm{CD} 11 \mathrm{c}^{+} \mathrm{CD} 8^{+}$dendritic cells for enhanced mucosal immunity. J Immunol 2004; 172: 3612-3619. 
36 Fukuiwa T, Sekine S, Kobayashi R, Suzuki H, Kataoka K, Gilbert RS et al. A combination of Flt3 ligand cDNA and CpG ODN as nasal adjuvant elicits NALT dendritic cells for prolonged mucosal immunity. Vaccine 2008; 26: 4849-4859.

37 Flores-Langarica A, Marshall JL, Hitchcock J, Cook C, Jobanputra J, Bobat $\mathrm{S}$ et al. Systemic flagellin immunization stimulates mucosal $\mathrm{CD} 103^{+}$dendritic cells and drives Foxp3 ${ }^{+}$regulatory $\mathrm{T}$ cell and IgA responses in the mesenteric lymph node. J Immunol 2012; 189: 5745-5754.

38 Ozawa Y, Suda T, Nagata T, Hashimoto D, Nakamura Y, Enomoto N et al. Mucosal vaccine using CTL epitope-pulsed dendritic cell confers protection for intracellular pathogen. Am J Respir Cell Mol Biol 2009; 41: 440-448.

39 Bonifaz LC, Bonnyay DP, Charalambous A, Darguste DI, Fujii S, Soares H et al. In vivo targeting of antigens to maturing dendritic cells via the DEC-205 receptor improves T cell vaccination. J Exp Med 2004; 199: 815-824.

40 Nochi T, Yuki Y, Matsumura A, Mejima M, Terahara K, Kim DY et al. A novel $M$ cell-specific carbohydrate-targeted mucosal vaccine effectively induces antigen-specific immune responses. J Exp Med 2007; 204: 2789-2796.

41 Lu L, Palaniyandi S, Zeng R, Bai Y, Liu X, Wang Y et al. A neonatal Fc receptor-targeted mucosal vaccine strategy effectively induces HIV-1 antigen-specific immunity to genital infection. J Virol 2011; 85: 10542-10553.

42 Tan X, Sande JL, Pufnock JS, Blattman JN, Greenberg PD. Retinoic acid as a vaccine adjuvant enhances $\mathrm{CD}^{+}{ }^{+} \mathrm{T}$ cell response and mucosal protection from viral challenge. J Virol 2011; 85: 8316-8327.

43 Woodrow KA, Bennett KM, Lo DD. Mucosal vaccine design and delivery. Annu Rev Biomed Eng 2012; 14: 17-46.

44 Benson MJ, Pino-Lagos K, Rosemblatt M, Noelle RJ. All-trans retinoic acid mediates enhanced $\mathrm{T}$ reg cell growth, differentiation, and gut homing in the face of high levels of co-stimulation. J Exp Med 2007; 204: 1765-1774.

45 Mora JR, Bono MR, Manjunath N, Weninger W, Cavanagh LL, Rosemblatt $M$ et al. Selective imprinting of gut-homing T cells by Peyer's patch dendritic cells. Nature 2003; 424: 88-93.

46 Iwata M, Hirakiyama A, Eshima Y, Kagechika H, Kato C, Song SY. Retinoic acid imprints gut-homing specificity on T cells. Immunity 2004; 21: 527-538.

47 Nacer A, Carapau D, Mitchell R, Meltzer A, Shaw A, Frevert U et al. Imaging murine NALT following intranasal immunization with flagellinmodified circumsporozoite protein malaria vaccines. Mucosal Immunol (e-pub ahead of print 3 July 2013; doi:10.1038/mi.2013.48).

48 Nudel I, Elnekave M, Furmanov K, Arizon M, Clausen BE, Wilensky A et al. Dendritic cells in distinct oral mucosal tissues engage different mechanisms to prime CD8 ${ }^{+}$T cells. J Immunol 2011; 186: 891-900.

49 Song JH, Nguyen HH, Cuburu N, Horimoto T, Ko SY, Park SH et al. Sublingual vaccination with influenza virus protects mice against lethal viral infection. Proc Natl Acad Sci USA 2008; 105: 1644-1649.

50 Song JH, Kim JI, Kwon HJ, Shim DH, Parajuli N, Cuburu N et al. CCR7-CCL19/CCL21-regulated dendritic cells are responsible for effectiveness of sublingual vaccination. J Immunol 2009; 182: 6851-6860.

51 Williamson E, Westrich GM, Viney JL. Modulating dendritic cells to optimize mucosal immunization protocols. J Immunol 1999; 163: 3668-3675.

(1)(2) This work is licensed under a Creative Commons Attribution-NonCommercial-ShareAlike 3.0 Unported License. To view a copy of this license, visit http:// creativecommons.org/licenses/by-nc-sa/3.0/ 